\title{
ALGUNS ASPECTOS PETROGRÁFICOS E GEOQUÍMICOS DO BATOLITO DE QUIXADÁ (CE)
}

\author{
HELIENE FERREIRA DÁ SILVA*
}

\begin{abstract}
SOME PETROGRAPHIC AND GEOCHEMICAL ASPECTS OF THE QUIXADÁ BATHOLITH (CE). The petrographic and geochemical characteristics of the plutonic body of Quixada in the Ceará State suggest the discrimination of two groups of rocks; a dominantly mesocratic and porphyritic one, with intermediate compositions (monzonitic to quartz-monzonitic) containing equigranular, dioritic to quartz-dioritic enclaves, and a group of equigranular and acid composition (granitic and granodioritic) that intruded the porphyritic rocks. The modal analyses on the Q-A-P diagram show two possible trends for these rocks; one from dioritic to granodioritic composition and another from dioritic-monzonitic to granitic composition. The porphyritic rocks, their enclaves, and the equigranular acid group exhibit on the $\mathrm{CaO}-\mathrm{Al}_{2} \mathrm{O}_{3}-\mathrm{K}_{2} \mathrm{O}+\mathrm{Na}_{2} \mathrm{O}$, respectivelly, a metaluminous and a peraluminous character. On Peacock's and AFM diagrams, the porphyritic rocks show a calc-alkaline character and the enclaves an alkali-calcic one. The equigranular group on the Wright diagram exhibit a calc-alkaline tendency. The field relationship, the petrographic aspects, and some chemical arguments corroborate the proposition of an hibrid origin for the porphyritic rocks, and to part of the equigranular acid group, as well. The enclaves seen to come from a different and independent source. The porphyritic group includes characteristically I-type granitoids and the equigranular acid group shows some chemical marks of both " $I$ " and " $S$ " type granitoids.
\end{abstract}

\begin{abstract}
RESUMO ALGUNS ASPECTOS PETROGRÁFICOS E GEOQUÍMICOS DO BATOLITO DE QUIXADÁ (CE). As características petrográficas e geoquímicas do corpo plutônico de Quixadá, no Estado do Ceará, sugerem a discriminação de dois tipos de rochas: um dominantemente mesocrático e porfirítico, de composiçăo intermediária (granítica e granodiorítica) contendo encraves dioríticos a quartzo dioríticos, equigranulares, e um grupo de composição ácida (granítica e granodiorítica), equigranular, que intrudiu as rochas porfiríticas. A análise modal no diagrama Q-A-P mostra duas possíveis tendências para estas rochas: uma de composiçấo diorítica a granodiorítica e outra de composição diorítica-monzonítica a granítica. As rochas porfiríticas, seus encraves e o grupo ácido equigranular exibem no diagrama $\mathrm{CaO}-\mathrm{Al}_{2} \mathrm{O}_{3}-\mathrm{K}_{2} \mathrm{O}+\mathrm{Na}_{2} \mathrm{O}$, um caráter respectivamente metaluminoso e peraluminoso. Nos diagramas de Peacock $\mathrm{e}$ AFM, as rochas porfiríticas mostram um caráter cálcio-alcalino e os encraves um caráter alcali-cálcico. O grupo equigranular, no diagrama de Wright, exibe uma tendência cálcio-alcalina. As relaçōes de campo, os aspectos petrográficos, e alguns argumentos geoquímicos corroboram a proposição de uma origem híbrida para as rochas porfiríticas e para parte do grupo equigranular ácido também. Os encraves parecem ter vindo de uma fonte diferente e independente. $O$ grupo porfirítico inclui granitóides caracteristicamente do tipo I e o grupo ácido equigranular mostra algumas características químicas de granitóides de ambos os tipos "I" e "S".
\end{abstract}

INTRODUÇÃo O corpo instrusivo de Quíxadá, Ceará, aflora a $160 \mathrm{~km}$ da capital numa extensão de aproximadamente $240 \mathrm{~km}^{2}$, com eiro maior de $30 \mathrm{~km}$ orientado na direção NE-SW.

O estudo das rochas deste batólito começou a ser delineado precisamente com o trabalho de Kawashita et al. (1976), que descrevem um corpo homogêneo monzonítico-sienítico encaixado em migmatitos, gnaisses e quartzo-monzonitos. Esses autores dataram algumas rochas deste batólito e obtiveram isócronas em torno de $530 \pm 19 \mathrm{Ma}$.

Souza \& Braga (1984) distinguiram petrograficamente neste corpo uma fácies granodiorítica sintectônica e uma granítica tarditectônica.

Com báse em critérios litológicos e estruturais, sugerimos duas unidades para esta regiäo - na mais antiga estâo as encaixantes (Complexo Ceará) do batólito, caracterizadas pelo caráter monocíclico da deformação pờ incluir uma seqüência parametamórfica (metapelitos, quartzitos, rochas cálcio-silicáticas) e migmatitos subordinados. A segunda unidade inclui um magmatismo-granitoide (monzonítico, quartzo-monzonítico, diorítico, quartzo-diorítico e granítico-granodiorítico) sin a tardicinemático relativo às zonas de cisalhamento dúcteis (ZCD) de Quixeramobim e Senador Pompeu.

\section{SÍNTESE DO MAPA GEOLÓGICO A escala deste}

trabalho nâo permite representar no esboço geológico (Figura 1) todos os tipos de rochas petrograficamente caracterizadas no corpo intrusivo de Quixadá. $O$ grupo de rochas félsicas ácidas e os encraves microgranulares não se encontram individualizados no mapa geológico, fois ocorrem em pequenas dimensōes. Os encraves não ultrapassam $2 \mathrm{~m}$ no maior alongamento e os diques félsicos ácidos apresentam larguras centimétricas e mais raramente de $4-5 \mathrm{~m}$, e comprimento de no máximo $80 \mathrm{~m}$. Essas rochas encontram-se distribuídas por todo o corpo.

As rochas deste batólito apresentam uma estruturaçâo geral NE-SW e suas foliações tectônicas e primárias (estrutura fluxional) estão verticalizadas.

Zonas de transiçầo onde coexistem granitos eqüigranulares, rochas porfirítica e quartzo-monzonitcs petrograficamente similares aos encraves da rccha porfirítica marcam o contato com as encaixantes da porção WNW deste batólito. Nas porçōes SE e NE, os contatos estão marcados por uma feição tectônica, representada pela zona de cisalhamento dúctil de Senador Pompeu, de aproximadamente $4 \mathrm{~km}$ de largura, de natureza destral, que se estende de SW para NE. Esta zona caracteriza-se principalmente pelo desenvolvimento de uma estrutura bandada na fácies porfirítica, ccm estiramento de seus fenocristais e transpoșição dos encraves.

$\mathrm{O}$ paralelismo entre as estruturas sin-magmáticas $e$ as * Geóloga, Companhia Integrada de Serviços Agropecuários de Pernambuco (Ċisagro). Kua Confederação do Equador, 111, Graças, CEP 52011,
Recife, PE 


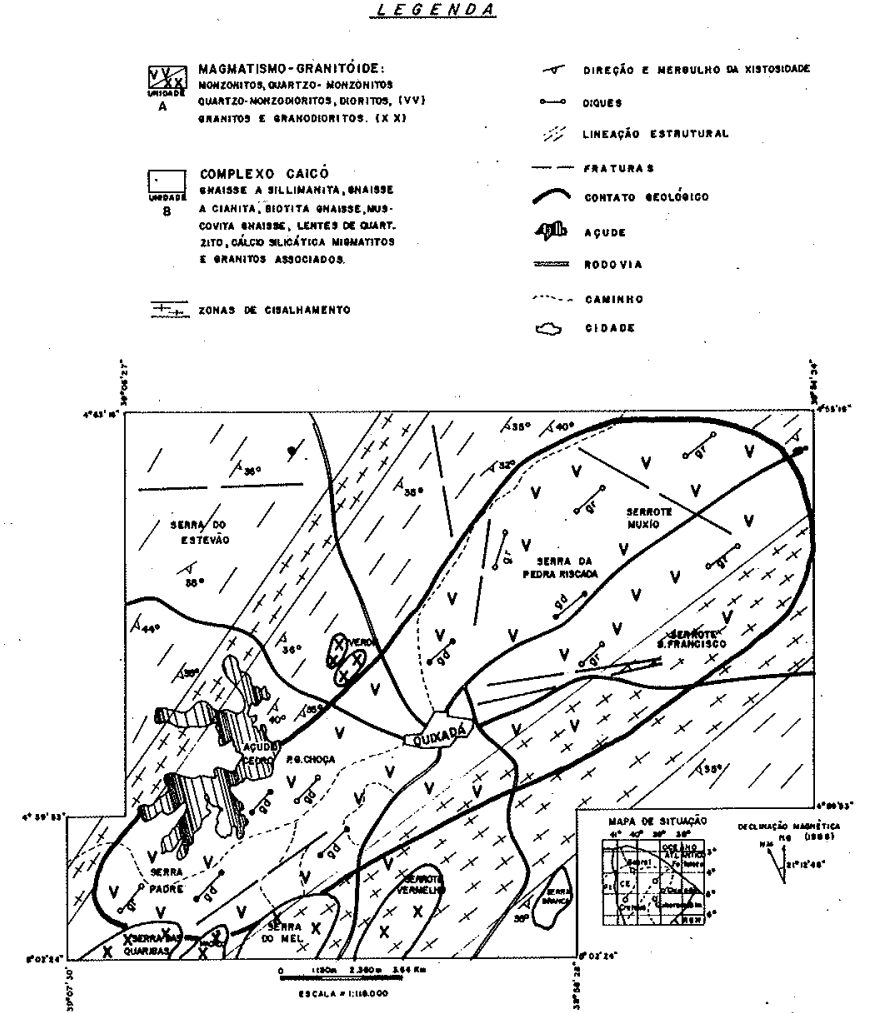

Figura 1 - Esboço geológico do batólito de Quixadá (CE) Figure 1 - Geological sketch of the Quixada Batholith (CE)

tectônicas, e a disposição vertical dos encraves e das feições cumulativas (clots de anfibólito e/ou biotita) são critérios estruturais que sustentam a idéia de intrusōes sin a tarditectônicas em relação às megatranscorrências dúcteis localizadas nas porções WNW, (zona de cisalhamento dúctil de Quixeramobim) e SSE, (zona de cisalhamento dúctil de Senador Pompeu) do batólito.

$\mathrm{O}$ fraturamento das rochas é comum por todo o batólito. As direções principais são $\mathrm{N}-\mathrm{S}, \mathrm{E}-\mathrm{W}$ e NE-SW.

PETRografiA Cinco tipos de rochas petrograficamente distintas foram caracterizadas nesta intrusão e consideradas aqui em dois grupos: um representado por uma fácies porfirítica de composição monzonítica e quartzo-monzonítica, e seus encraves de composição dioríticas e quartzo-dioríticas; e outro representado por diques eqüigranulares félsicos de composição granítica e granodiorítica.

A análise modal (Fig. 2), com base nos critérios de Hutchison (1974), para estas rochas mostra dois trends composicionais possíveis e predominantes, um diorítico quartzo-monzonítico a granítico e outro diorítico a granodiorítico, que pode ser enquadrado na subsérie monzonítica e/ou granodiorítica de Lameyere \& Bowden (1982). A Figura 2 discrimina petrograficamente os dois tipos de análises modais realizados na fácies porfirítica; uma desenvolvida a nível de campo, baseando-se no métodó de Hutchison (op. cit.) para análises modais em rochas porfiríticas e numa etapa seguinte análises modais apenas da matriz, excluindo os fenocristais.

O tipo porfirítico monzonítico a quartzo-monzonítico apresenta índice de cor variando de $18,83 \%$ a $30,27 \%$ e contém fenocristais de microclina, plagioclásio, que atingem dimensões de até $8 \mathrm{~cm}$ de maior alongamento. Sua matriz consiste essencialmente em anfibólio, biotita, plagioclásio

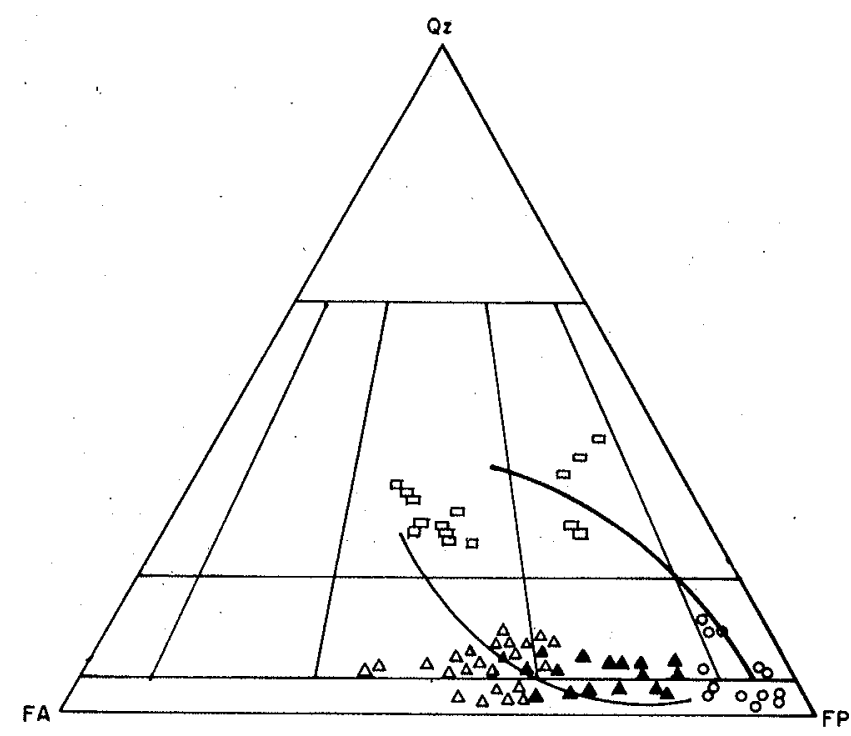

Figura 2 - Análises modais para as rochas graníticas do batólito de Quixadá:

$\triangle$ fácies porfirítica (rocha total);

$\Delta$ fácies porfirítica (matriz);

$\bigcirc$ encraves microgranulares;

$\square$ fácies eqüigranular tardia

Figure 2-Modal analysis of the Quixadá Batholith granitic rocks

(predominando o oligoclásio, $\left.A n_{8-11}\right)$ e a albita $\left(A n_{4-5}\right)$ é o feldspato alcalino da matriz. Apatita, zircão e titanita são os acessórios principais. No campo, localmente, observam-se cristais de feldspato alcalino com formas ovóides marcados por um manto de plagioclásio compondo a textura rapakivi, que, segundo Hibbard (1981), é uma feição típica de granitos híbridos.

As estruturas fluidas na fácies porfirítica se evidenciam pelo alinhamento dos fenocristais de feldspatos que esporadicamente sugerem uma feição do tipo entelhamento, definindo um sentido preferencial do fluxo magmático de $\mathrm{NE}$ para SW.

Na Serra do Padre (porção SW do batólito) e Pedra da Galinha Choca (porção Central da intrusão), feições cumulativas constituídas principalmente por anfibólio e biotita subordinadamente alternam-se com cumulatos de feldspatos, sugerindo um acamamento (layering) primário.

$O$ anfibólio na fácies porfirítica ocorre em duas gerações: a hornblenda numa primeira (com pleocroísmo verde-intenso e $2 \mathrm{~V}$ em torno de $50^{\circ}$ ) e a actinolita tardia (com pleocroísmo verde-pálido e $2 \mathrm{~V}$ em torno de $70^{\circ}$ ). A biotita também cristalizou em duas geraçōes: a primeira freqüentemente inclusa no plagioclásio e outra tardia gerada às expensas do anfibólio. A presença sistemática da biotita, como inclusão no plagioclásio, é um critério petrográfico que pode sugerir uma rocha-fonte inicialmente enriquecida em $\mathrm{K}_{2} \mathrm{O}$.

Os clots de biotita e/ou anfibólio nesta fácies, e o fato de essas fases se desenvolverem em duas gerações, são critérios que mostram efeitos de assimilação desta rocha com outros tipos (possivelmente com seus encraves). $O$ piroxênio reliquiar freqüiente no anfibólio seria a fase incorporada do magma mais básico.

Encraves microgranulares dioríticos a quartzo-dioríticos são abundantes no tipo porfirítico, apresentando-se com formas abauladas, mais raramente angulosas e de preferência dispersos na porção NE da intrusão, como enxames.

A mineralogia desses encraves é semelhante à da fácies porfirítica. $O$ plagioclásio (oligoclásio-andesina), o anfibólio e 
Tabela 1 - Análises químicas para os elementos maiores para as rochas intrusivas do batolito de Quixadá Table 1 - Major elements chemical analysis for the intrusive rocks of the Quixadá Batholith

\begin{tabular}{|c|c|c|c|c|c|c|c|c|c|c|c|c|c|}
\hline & $\operatorname{Ln}(O)$ & $\operatorname{Ln}(O)$ & $\operatorname{Ln}(O)$ & $\operatorname{Ln}(\Delta)$ & $\operatorname{Ln}(\Delta)$ & $\operatorname{Ln}(\Delta)$ & $\operatorname{Ln}(\Delta)$ & $\operatorname{Ln}(\triangle)$ & $\operatorname{Ln}(\Delta)$ & $\ln (\triangle)$ & $\operatorname{Ln}(\square)$ & $\operatorname{Ln}(\square)$ & $\operatorname{Ln}(\square)$ \\
\hline $\mathrm{SiO}_{2}$ & 53,70 & 55,20 & 55,10 & 59,10 & 59,30 & 59,10 & 56,90 & 58,00 & 58,30 & 65,00 & 73,00 & 71,30 & 69,00 \\
\hline $\mathrm{TiO}_{2}$ & 0,82 & 0,81 & 0,98 & 0,78 & 0,71 & 0,79 & 0,78 & 0,77 & 0,85 & 0,58 & 0,23 & 0,35 & 0,22 \\
\hline $\mathrm{Al}_{2} \mathrm{O}_{3}$ & 14,90 & 16,50 & 17,70 & 15,80 & 15,80 & 15,20 . & 15,70 & 15,00 & 16,00 & 14,10 & 14,90 & 15,10 & 15,90 \\
\hline $\mathrm{Fe}_{2} \mathrm{O}_{3}$ & 2,30 & 2,60 & 2,30 & 1,60 & 1,40 & 1,50 & 1,30 & 1,30 & 1,30 & 0,60 & 0,42 & 1,00 & 0,38 \\
\hline $\mathrm{FeO}$ & 4,32 & 3,17 & 4,32 & 3,31 & 3,00 & 3,60 & 4,03 & 3,89 & 3,89 & 2,88 & 0,70 & 0,72 & 0,65 \\
\hline $\mathrm{MnO}$ & 0,142 & 0,099 & 0,164 & 0,088 & 0,070 & 0,099 & 0,101 & 0,099 & 0,091 & 0,069 & 0,027 & 0,028 & 0,023 \\
\hline MgO & 7,70 & 5,00 & 3,28 & 4,50 & 4,50 & 4,90 & 5,80 & 5,90 & 4,20 & 2,90 & 0,44 & 0,50 & 0,56 \\
\hline $\mathrm{CaO}$ & 6,90 & 6,70 & 6,10 & 5,80 & 5,50 & 6,10 & 6,30 & 5,80 & 6,10 & 3,80 & 1,40 & 1,60 & 1,90 \\
\hline $\mathrm{Na}_{2} \mathrm{O}$ & 2,80 & 4,10 & 4,00 & 3,60 & 4,00 & 3,50 & 3,20 & 3,70 & 3,30 & 4,00 & 3,50 & 3,60 & 5,60 \\
\hline $\mathrm{K}_{2} \mathrm{O}$ & 4,50 & 3,80 & 3,80 & 3,60 & 4,30 & 3,70 & 3,80 & 3,80 & 3,50 & 4,70 & 4,30 & 4,70 & 3,60 \\
\hline $\mathrm{P}_{2} \mathrm{O}_{5}$ & 0,63 & 0,57 & 0,67 & 0,55 & 0,51 & 0,61 & 0,58 & 0,56 & 0,57 & 0,34 & 0,06 & 0,11 & 0,87 \\
\hline $\mathrm{CO}_{2}$ & $<0,05$ & 0,10 & 0,20 & $<0,05$ & 0,07 & 0,07 & 0,07 & 0,07 & 0,14 & $<0,05$ & $<0,05$ & 0,07 & 0,14 \\
\hline $\mathrm{H}_{2} \mathrm{O}^{+}$ & 1,09 & 1,01 & 1,21 & 1,02 & 0,81 & 0,90 & 1,11 & 0,99 & 1,05 & 0,80 & 0,66 & 0,58 & 0,55 \\
\hline $\mathrm{H}_{2} \mathrm{O}^{-}$ & 0,16 & 0,13 & 0,07 & 0,17 & 0,11 & 0,01 & 0,17 & 0,00 & 0,19 & 0,14 & 0,12 & 0,00 & 0,14 \\
\hline TOTAL & 100,01 & 99,79 & 99,81 & 99,97 & 100,08 & 100,08 & 99,84 & 99,88 & 99,48 & 99,96 & 99,80 & 99,66 & 99,53 \\
\hline
\end{tabular}

$(\triangle)=$ Fácies porfirítica

(O) = Encraves microgranulares

(口) = Fácies equigranular tardia

$\mathrm{Ln}=$ Referência das amostras

Tabela 2 - Análises químicas para os elementos traços para as rochas intrusivas do batolito de Quixadá Table 2 - Trace elements chemical analysis for the intrusive rocks of the Quixada Batholith

\begin{tabular}{r|r|r|r|r|r|r|r|r|r|r|r|r|r}
\hline & $\operatorname{Ln}(O)$ & $\operatorname{Ln}(O)$ & $\operatorname{Ln}(O)$ & $\operatorname{Ln}(\triangle)$ & $\operatorname{Ln}(\Delta)$ & $\operatorname{Ln}(\Delta)$ & $\operatorname{Ln}(\Delta)$ & $\operatorname{Ln}(\Delta)$ & $\operatorname{Ln}(\Delta)$ & $\operatorname{Ln}(\Delta)$ & $\operatorname{Ln}(\square)$ & $\operatorname{Ln}(\square)$ & $\operatorname{Ln}(\square)$ \\
\hline $\mathrm{Sn}$ & $<5$ & $<5$ & $<5$ & $<5$ & $<5$ & $<5$ & $<5$ & $<5$ & $<5$ & $<5$ & $<5$ & $<5$ & $<5$ \\
$\mathrm{Ba}$ & 3200 & 2650 & 3030 & 2840 & 2860 & 2270 & 2500 & 2000 & 2000 & 1970 & 2030 & 1220 & 1620 \\
$\mathrm{Nb}$ & 26 & $<20$ & $<20$ & 30 & $<20$ & $<20$ & $<20$ & $<20$ & $<20$ & $<20$ & $<20$ & $<20$ & $<20$ \\
$\mathrm{Li}$ & 12 & 20 & 17 & 12 & 9 & 11 & 5 & 12 & 16 & 9 & 12 & 11 & 8 \\
$\mathrm{Zn}$ & 200 & 158 & 60 & 200 & 156 & 190 & 170 & 240 & 240 & 114 & 130 & 73 & 76 \\
$\mathrm{Be}$ & $<2$ & $<2$ & $<2$ & $<2$ & $<2$ & $<2$ & $<2$ & $<2$ & $<2$ & $<2$ & $<2$ & $<2$ & $<2$ \\
$\mathrm{~Pb}$ & 35 & 50 & 50 & 50 & 40 & 40 & 35 & 35 & 45 & 45 & 40 & 45 & 30 \\
$\mathrm{Sr}$ & 1600 & 2150 & 1710 & 2000 & 2000 & 1820 & 2000 & 1770 & 1640 & 1310 & 668 & 718 & 1628. \\
$\mathrm{Rb}$ & 88 & 74 & 70 & 67 & 64 & 67 & 60 & 66 & 61 & 50 & 110 & 24 & 57 \\
\hline
\end{tabular}

$(\Delta)=$ Fácies porfirf́tica

(O) $=$ Encraves microgranulares

(口) = Fácies equigranular tardia

$\mathbf{L} \mathbf{n}=$ Referência das amostras 
a biotita são as fases essenciais e a da microclina subordinada. $O$ anfibólio e a biotita também se formaram em đuas gerações e mantêm freqüente relação de idiomorfismo com o epídoto magmático. Este epídoto ocorre em cristais euedrais freqüentemente incluso na biotita $e$ exibe feição de embainhamento com 0 anfibólito. A presença do epídoto magmático nesses encraves indica, segundo os critérios de Zen (1985), Zen \& Hammarström (1984), que sua cristalização se deu a pressōes entre $6 \mathrm{e} 8 \mathrm{~kb}$.

Na porção norte do batólio, aflora um tipo petrográfico de composição modal diorítica semelhante aos encraves inclusos na fácies porfirítica apresentando uma feição (contatos crenulados) sugestiva de coexistência e/ou mistura de dois tipos de magmas de composição intermediária. Esta feição indica ainda que a mistura se desenvolveu próximo ao local do posicionamento dessas rochas.

O grupo de rochas félsicas de composição granítica e granodiorítica ocorre como intrusões (dique na fácies porfirítica). Estes diques apresentam larguras centimétricas (máximo de $80 \mathrm{~cm}$ ) e poucas dezenas de metros de comprimento. São freqüentes os xenólitos da fácies porfirítica nesses corpos. A maior parte das rochas deste grupo apresenta textura eqüigranular e apenas uma fácies porfirítica foi mapeada na porção SW do batólito, na Serra dos Macacos. Essas rochas contêm essencialmente quartzo, oligoclásio, microlina e biotita. Apatita, titanita, allanita e zircão são seus acessórios.

\section{GEOQUímICA Elementos Maiores Treze amostras} das rochas mapeadas no corpo intrusivo de Quixadá foram analisadas quimicamente: sete da fácies porfirítica, três dos encraves dioríticos e três das rochas félsicas tardias. A reduzida quantidade de análises químicas para os encraves e para os diques félsicos tardios torna as consideraçōes a seguir passíveis de reinterpretaçōes posteriores.

Os teores químicos e alguns dados petroquímicos para essas rochas estão mostrados, respectivamente, nas tabelas $1 \mathrm{e}$ 2.

A fácies porfirítica monzonítica, quartzo-monzonítica apresenta teores de $\mathrm{SiO}_{2}$ entre $56,9 \%$ e $65 \%$ de $\mathrm{Al}_{2} \mathrm{O}_{3} \mathrm{com}$ média de $15,37 \%$, por altos valores de $\mathrm{Na}_{2} \mathrm{O}$ (média 4,3\%), $\mathrm{K}_{2} \mathrm{O}$ com $3,9 \%$ (em média) e $\mathrm{CaO}$ com $5,6 \%$ em média. Os altos teores em $\mathrm{CaO}$ e $\mathrm{K}_{2} \mathrm{O}$ nessas rochas resultaram na cristalização precoce do anfíbólio e da biotita mesmo antes do plagioclásio. $O$ indice agpaítico indica seu cunho metaluminoso, sustentado ainda por valores de $\mathrm{Al}_{2} \mathrm{O}_{3}$, inferiores à soma dos álcalis mais o cálcio $\left(\mathrm{CaO}+\mathrm{K}_{2} \mathrm{O}+\right.$ $\mathrm{Na}_{2} \mathrm{O}$ ). Projeções moleculares no diagrama $\mathrm{CaO}-\mathrm{Al}_{2} \mathrm{O}_{3}-\mathrm{K}_{2} \mathrm{O}$ $+\mathrm{Na}_{2} \mathrm{O}$ de Loiselle \& Wones (1979) (Fig. 3) mostram o tipo químico desta fácies e sua classificação no grupo dos granitóides tipo I. Os altos valores de $\mathrm{Na}_{2} \mathrm{O}$ (maior que 3,2\%) e de $\mathrm{Fe}^{+3} / \mathrm{Fe}^{+2}+\mathrm{Fe}^{+3}$ (entre $0,157 \%$ e $0,302 \%$ ) são típicos de granitos tipo I, segundo os critérios de Chappel (1984) e Chappel \& White (1974).

No diagrama AFM (Fig. 4) observa-se que a variação química dessas rochas se faz do tipo cálcio-alcalino para o alcalino.

Os encraves dioríticos e quartzo-dioríticos apresentam valores de $\mathrm{SiO}_{2}$ entre $53,3 \%$ e $55,2 \%$ e de $\mathrm{Al}_{2} \mathrm{O}_{3}$ entre $14,90 \%$ e $17,7 \%$. Seus teores de $\mathrm{K}_{2} \mathrm{O}$ com média de $4 \%$ e $\mathrm{CaO}$ com média de $6,5 \%$ superam aqueles da fácies porfirítica, com exceção do valor em $\mathrm{Na}_{2} \mathrm{O}(3,6 \%)$.

No diagrama $\mathrm{CaO}-\mathrm{Al}_{2} \mathrm{O}_{3}-\mathrm{K}_{2} \mathrm{O}+\mathrm{Na}_{2} \mathrm{O}$ (Fig.3), esses encraves mostram uma tendência metaluminosa a peraluminosa. Seu tipo químico mostrado no diagrama de Wright (1969) (Fig. 5) é predominantemente cálcio-alcalino, entretanto o diagrama de Peacock (1931) mostra uma tendência prodominantemente álcali-cálcica (Fig. 6).

Os granitos e granodioríticos tardios (grupo félsico) apresentam altos valores de $\mathrm{SiO}_{2}$ (média de 71,36\%), $\mathrm{Al}_{2} \mathrm{O}_{3}$

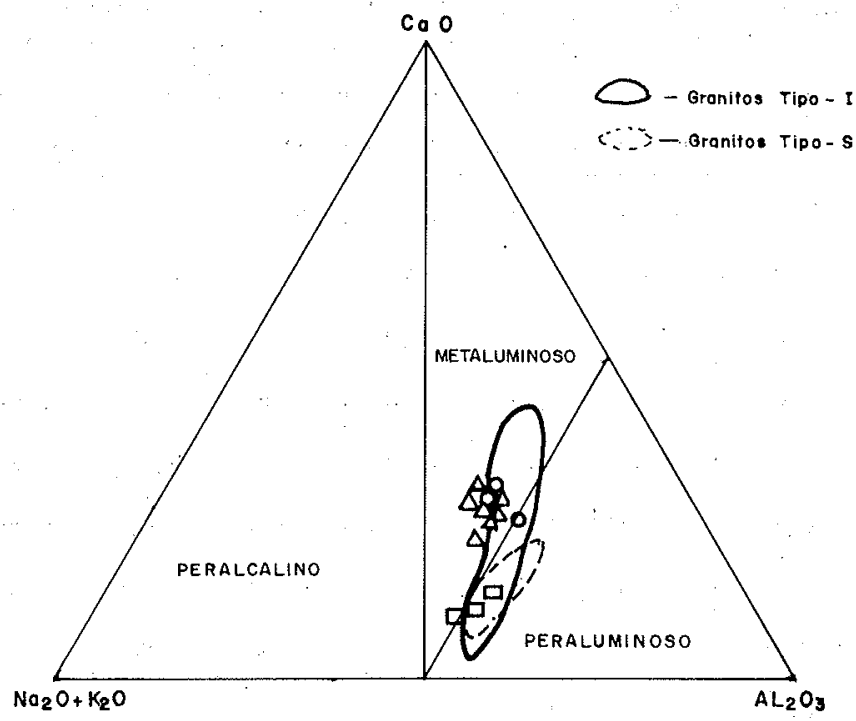

Figura 3 - Projeção molecular no diagrama $\mathrm{CaO}-\mathrm{Al}_{2} \mathrm{O}_{3}-\mathrm{K}_{2} \mathrm{O}+\mathrm{Na}_{2} \mathrm{O}$ de Loiselle \& Wones (1979). Os campos dos granitóides tipos I e $S$ são mostrados: $\square$ fácies eqüigranular; $\triangle$ fácies porfirica; $O$ encraves dioríticos

Figure 3 - Molecular projection in the $\mathrm{CaO}-\mathrm{Al}_{2} \mathrm{O}_{3}-\mathrm{K}_{2} \mathrm{O}+\mathrm{Na}_{2} \mathrm{O}$ diagram (Loiselle \& Wones 1979). The fields of $\mathrm{I}$ and $\mathrm{S} S$-type granitoids are shown $\square$ equigranular facies; $\Delta$ porphyritic facies; $O$ dioritic enclaves

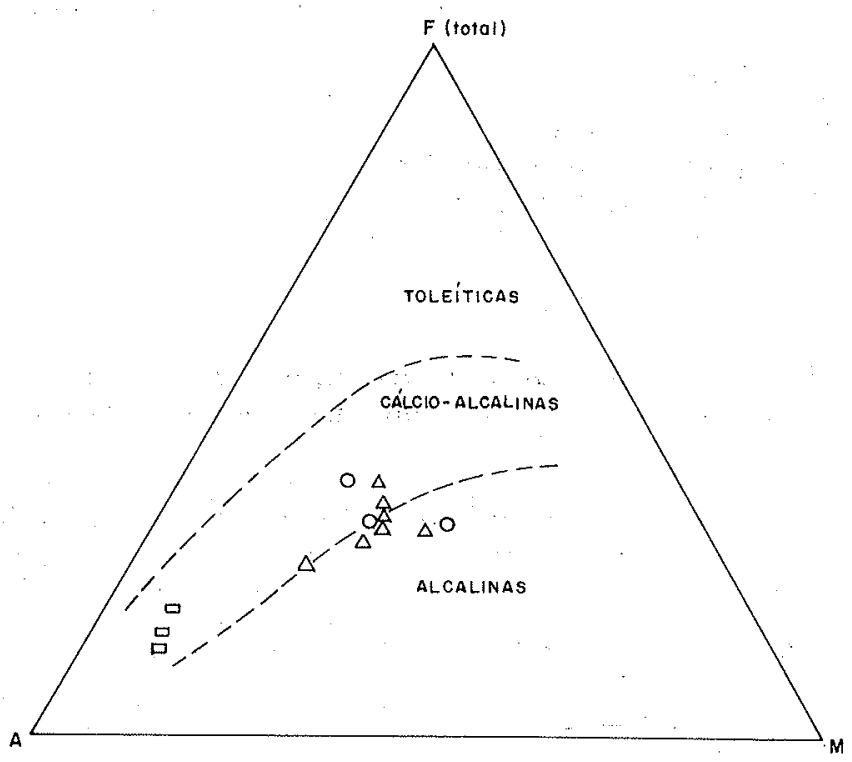

Figura 4 - Diagrama AFM mostrando o comportamento transicional cálcio-alcalino a alcalino para os encraves dioríticos (O) e para a fácies porfirítica $(\Delta)$. Os granitos eqüigranulares tardios: (口) mostram uma tendência peralcalina

Figure 4 - AFM diagram showing the calc-alkaline to alkaline transitional behavior to the dioritic enclaves $(O)$ and to the porphyrithic facies $(\triangle)$. The tardi equigranular granites exhibit a peralkaline trend

variando de $14,90 \%$ a $15,90 \%$, de $\mathrm{Na}_{2} \mathrm{O}$ com $4,2 \%$ (em média), $\mathrm{CaO}$ com média de $1,6 \%$ e $\mathrm{K}_{2} \mathrm{O}$ com $4,2 \%$ em média. As projeçōes no diagrama Qz-Ab-Or (Fig. 7), modificado de Cox et al. (1979), revelam nesta fácies uma composição próxima do mínimo granítico. As projeções moleculares no diagrama $\mathrm{CaO}-\mathrm{Al}_{2} \mathrm{O}_{3}-\mathrm{K}_{2} \mathrm{O}+\mathrm{Na}_{2} \mathrm{O}$ (Fig. 3) mostram seu 


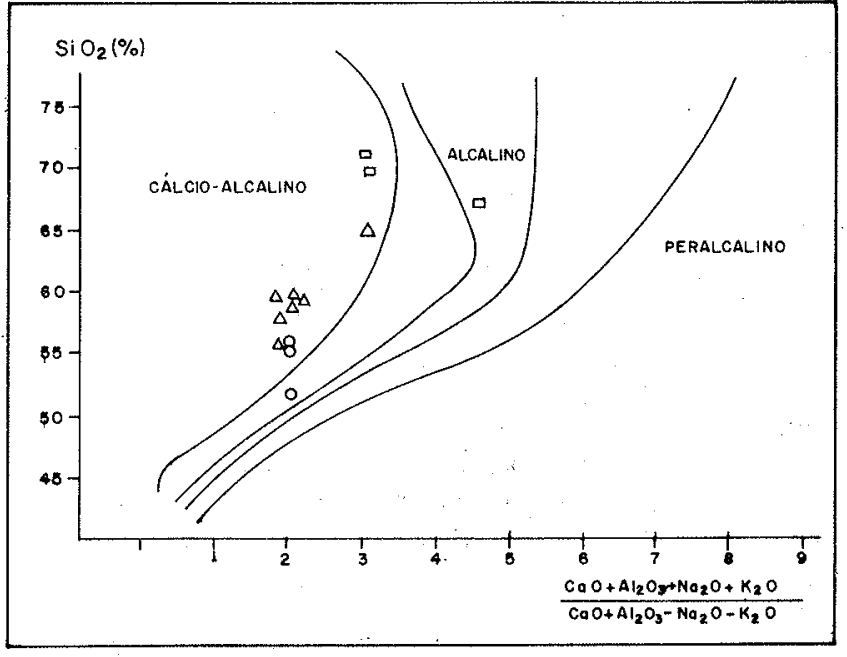

Figura 5 - Diagrama de Wright (1969) mostrando composições predominantemente cálcio-alcalinas para todas as rochas do batólito de Quixadá. Uma amostra dos encraves dioríticos (O) e da fácies eqüigranular tardia ( $\square$ )mostra caráter alcalino $\triangle$ Fácies porfirítica

\section{$\triangle$ Fácies porfirítica}

Figure 5 - Wright diagram (1969) showing predominant calc-alkaline composition for all the rocks from Quixada Batholith. One sample of the dioritic enclaves $(O)$ and tardi equigranular facies ( $\square$ ) exhibit alkaline character

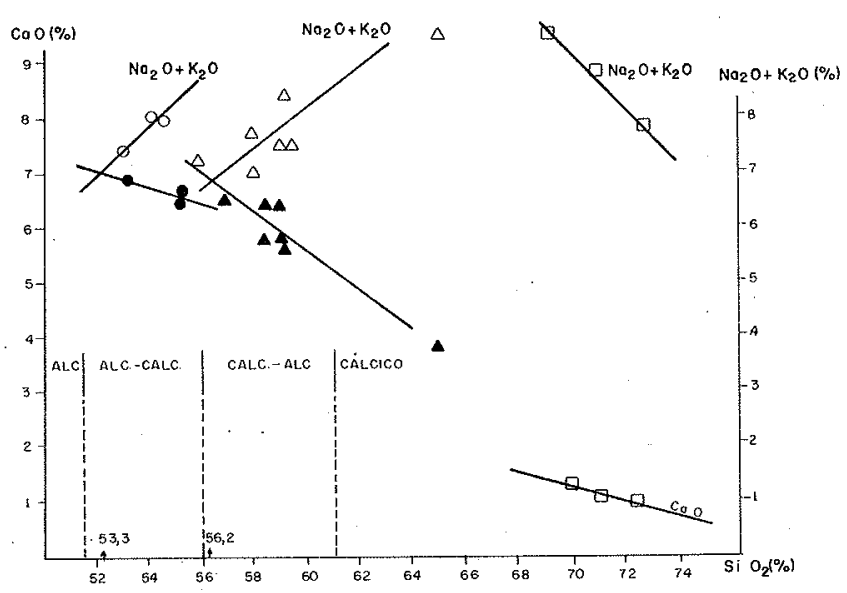

Figura 6 - $O$ índice de Peacock (1931) mostra um caráter álcali-cálcico para os encraves dioríticos $(O)$ e transicional, entre álcali-cálcico e cálcio-alcalino, para a fácies porfitítica $(\triangle)$ e nada define para os granitos equigranulares $(\square)$

Figure 6 - The Peacock index (1931) shows a alkali-calcic character to the dioritic enclaves $(O)$ and transitional, from alkali-calcic to calcic-alkaline, to the porphyritic facies $(\bar{\Delta})$ and defines nothing to the equigranular granites $(\square)$

caráter predominantemente peraluminoso e a presença de granitos tipo "I" e "S" neste grupo de rochas. O diagrama AFM (Fig. 4) revela ainda uma tendência peralcalina para esses tipos.

Elementos Menores De uma maneira geral, o comportamento dos elementos-traços nas rochas do batólito de Quixadá é normal tratando-se de granitos predominantemente cálcico-alcalinos.

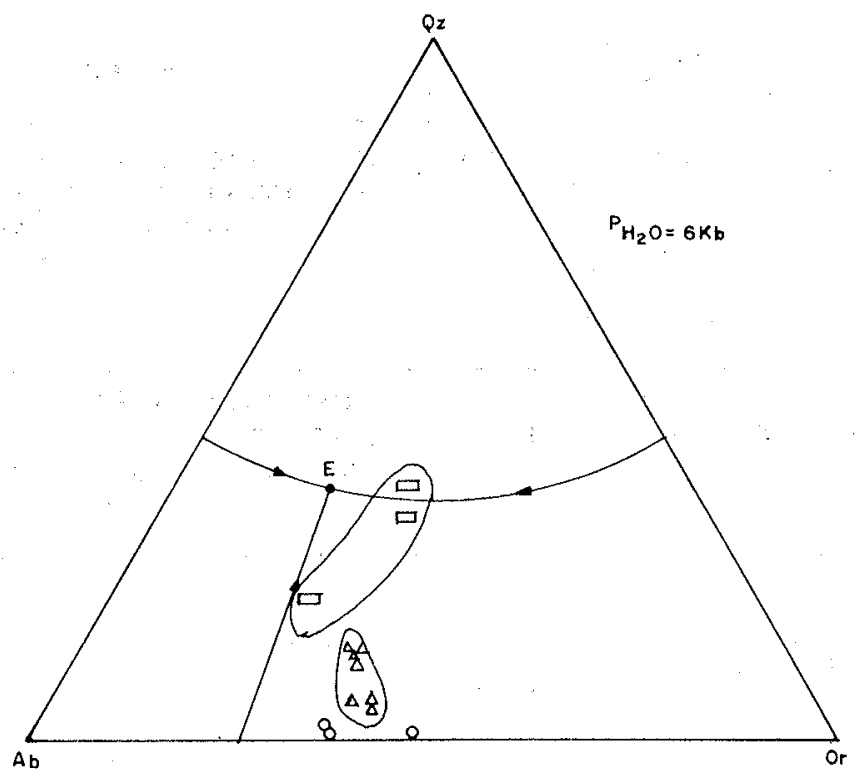

Figura 7 - Diagrama para composição do líquidos no sistema $\mathrm{Ab}-\mathrm{Or}-\mathrm{SiO}_{2}$ e para as rochas do batólito de Quixadá a pressóes de $6 \mathrm{~Kb}$ (adaptado de Cox et al. 1979, pós Tuttle \& Bowen 1958):

$\square$ fácies eqüigranular tardia;

$\triangle$ fácies porfiritica;

O encraves microgranulares

Figure 7 - Diagram for the liquidus composition in the $\mathrm{Ab}-\mathrm{Or}-\mathrm{SiO}_{2}$ system and to the Quixada Batholith rocks at $6 \mathrm{~Kb}$ pressures (adopted from Cox et al. 1979, after Tuttle \& Bowen 1958). Symbols as above

A boa correlação positiva do $\mathrm{Ba}$ contra o $\mathrm{Rb}$ e $\mathrm{K}$ (Fig. 8) mostra a retenção desses elementos pela biotita $\mathrm{e}$ pelo feldspato potássico.

A correlação positiva do Ba contra o $\mathrm{Sr}$ (Fig. 9) na fácies porfirítica pode ser justificada pelo simultâneo fracionamento da biotita e do plagioclásio. A correlação negativa entre o $\mathrm{Ba}$ e o $\mathrm{Sr}$ para os encraves mostra a retenção do $\mathrm{Sr}$ pelo plagioclásio.

CONCLUSõEs Pensa-se que algumas rochas do grupo félsico eqüigranular se tenham formado após contaminação com o magma gerador do corpo diorítico aflorante ao norte, $\mathrm{e}$ que os inúmeros encraves microgranulares espalhados por todo o batólito e a própria fácies porfirítica poderiam ser o produto dessa mistura. Nos diagramas binários observa-se que os valores químicos da fácies porfirítica estão sistematicamente dispostos entre os dos encraves e do grupo félsico tardio, comportamento que sustenta as idéias acima expostas.

A presença do epídoto magmático nos encraves é indicativa de que essas rochas se cristalizaram a grandes profundidades crustais $(25-30 \mathrm{~km})$ e sob pressôes litostáticas entre 6 e $8 \mathrm{~kb}$. Na maioria dos diagramas de variação química são observados trends independentes de sua hospedaria, que possivelmente sugerem uma fonte desses encraves diferente das demais rochas do batólito. Defende-se, portanto, para esses tipos uma origem essencialmente mantélica (fusão parcial de uma componente crustal).

O caráter peraluminoso, a ausência do diopsídio normativo, o $\mathrm{Al}_{2} \mathrm{O}_{3} / \mathrm{CaO}+\mathrm{Na}_{2} \mathrm{O}+\mathrm{K}_{2} \mathrm{O}$ maior que 1,1 , os altos teores de $\mathrm{SiO}_{2}(71 \%, 73 \%)$ e os freqüentes encraves surmicáceos são argumentos fortes a favor de uma origem principalmente 
Tabela 3 - Classificação química para rochas intrusivas do batolito de Quixadá

Table 3 - Chemical classification for the intrusive rocks of the Quixada Batholith

\begin{tabular}{|c|c|c|}
\hline $\begin{array}{c}\text { PRINCIPAIS } \\
\text { CARACTERISTICAS }\end{array}$ & PETROGRÁFICAS & QUÍMICAS \\
\hline $\begin{array}{l}\text { SUBSÉRIE MONZONÍTICA } \\
\text { E } \\
\text { ENCRAVES MICROGRA- } \\
\text { NULARES } \\
\text { (TIPO I) }\end{array}$ & $\begin{array}{l}\text { - HORNBLENDA COMO MÁFICOS DOMINANTES } \\
\text { - ENCRAVES RICOS EM HORNBLENDA } \\
\text { - TITANITA COMO ACESSÓRIO PRINCIPAL }\end{array}$ & $\begin{array}{l}-\mathrm{Al}_{2} \mathrm{O}_{3} / \mathrm{Na}_{2} \mathrm{O}+\mathrm{CaO}-\mathrm{K}_{2} \mathrm{O}, 1,1 \\
\text { - } \text { AMPLA VARIAĆÃO COMPOSICIONAL } \\
\text { COM FÁCIES FÉLSICOS A MÁFICOS } \\
\text { - DIOPSIDIO NA NORMA } \\
\text { - ALTAS RAZÖES Fe } \mathrm{Fe}^{+3} / \mathrm{Fe}^{+3}+\mathrm{Fe}^{+2} \\
\text { - } \mathrm{Na}_{2} \mathrm{O}>3,2 \%\end{array}$ \\
\hline $\begin{array}{l}\text { GRANITOS FÉLSICOS } \\
\text { EQUIGRANULARES } \\
\text { TARDIOS } \\
\text { (TIPO S) }\end{array}$ & $\begin{array}{l}\text { - MOSCOVITA EM CERTAS FÁCIES E BIOTITA } \\
\text { EM OUTRAS } \\
\text { - ENCRAVES SURMICÁCEOS }\end{array}$ & $\begin{aligned}- & \mathrm{Al}_{2} \mathrm{O}_{3} / \mathrm{Na}_{2} \mathrm{O}+\mathrm{CaO}+\mathrm{K}_{2} \mathrm{O}>1,1 \\
\text { - } & \text { RESTRIÇÃO COMPOSICIONAL COM } \\
& \text { ALTOS VALORES PARA SiO }{ }_{2}-71,73 \% \\
\text { - } & \text { SEM DIOPSÍDIO NA NORMA }\end{aligned}$ \\
\hline
\end{tabular}

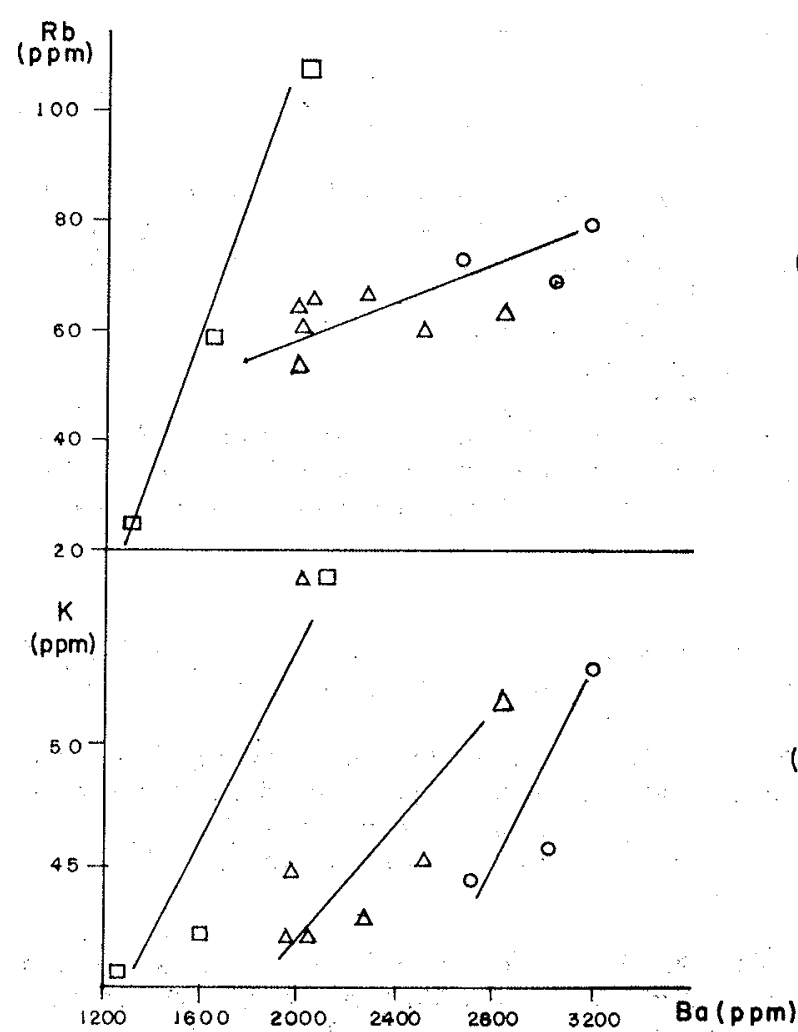

Figura 8-Correlações positivas entre o $\mathrm{Rb}$ e $\mathrm{Ba}$ (a) e o $\mathrm{K}$ e $\mathrm{Ba}$ (b), para todas as rochas do batólito de Quixadá: $\bigcirc$ encraves dioríticos; $\triangle$ fácies porfirítica; $\square$ fácies eqüigranular tardia

Figure 8 - Positive correlations between $(a) \mathrm{Rb}$ and $\mathrm{Ba}$, and $(b) \mathrm{K}$ and $\mathrm{Ba}$, for all the rocks from the Quixada Batholith symbols as above

crustal para as rochas que constituem o grupo félsico tardio. As relações de campo sugerem um sin-plutonismo (ou intrusōes sincrônicas) dessas rochas com a fácies porfirítica dominante no batólito.

A seqüência de eventos proposta para este batólito inicia-se com a fusão parcial de um magma básico produzido o magma diorítico representado pelos diorítos aflorantes ao norte do corpo intrusivo, e possivelmente alguns encraves microgranulares que se encontram inclusos na fácies porfirítica. Este magma derivado teria sido contaminado por uma componente crustal, provavelmente de composição granodiorítica (cujos representantes são comuns a sul do

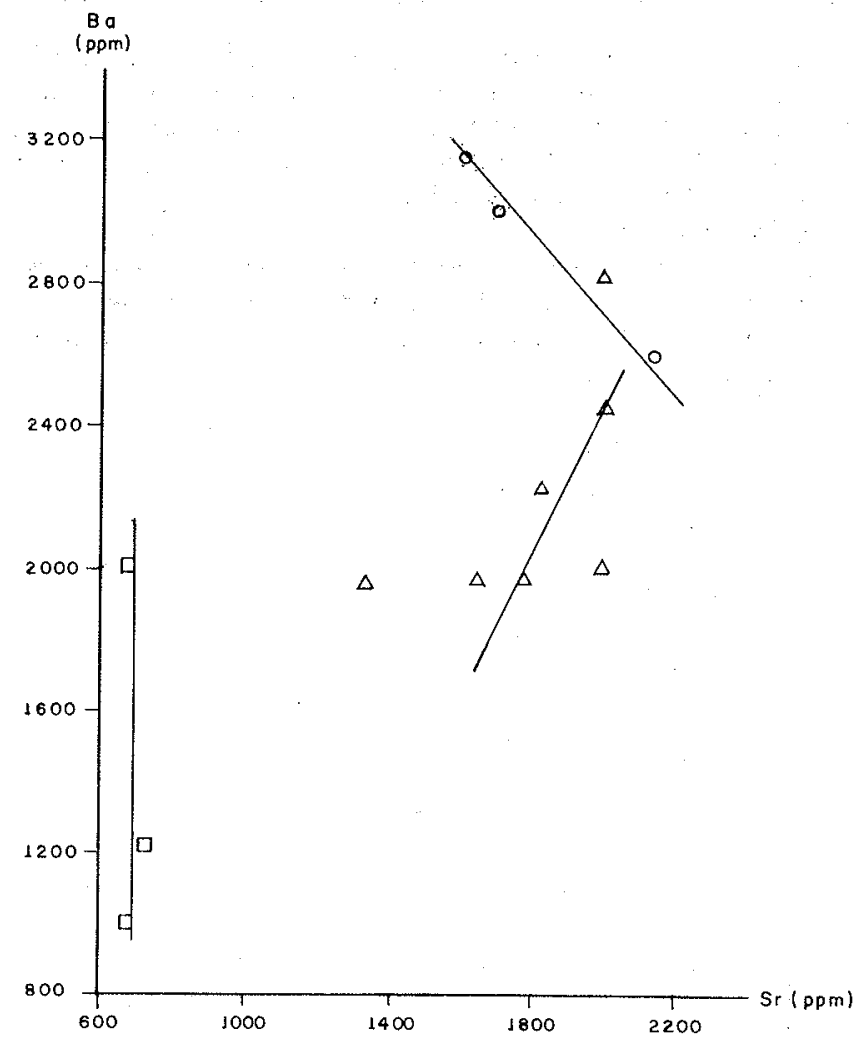

Figura 9 - Correlação negativa entre o Ba e Sr para os encraves dioríticos $(O)$ e positiva para a fácies porfirítica $(\Delta)$. $\mathrm{Na}$ fácies eqüigranular ( $\square)$, os valores mostram-se relativamente constantes para o $\mathrm{Sr}$ e amplos para o $\mathrm{Ba}$

Figure 9 - Negative correlations between $\mathrm{Ba}$ and $\mathrm{Sr}$ to the dioritic enclaves $(O)$ and positive to the porphyritic facies $(\triangle)$. There is a constancy for the $\mathrm{Sr}$ values of the equigranular facies $(\square)$

batólito), gerando as fácies mais ácidas (granito, campo 3a de Streckeisen 1976).

Agradecimentos Este trabalho é parte da Dissertação de Mestrado intitulada Petrografia e Geoquímica do Batólito de Quixadá, defendida e aprovada em setembro de 1987 na Universidade Federal de Pernambuco. Somos gratos ao Conselho Nacional de Desenvolvimento Científico e Tecnológico $(\mathrm{CNPq})$, pelo suporte financeiro que possibilitou a realização da referida dissertação; e ao Professor Dr. Hartmut Beurlen (UFPE), pela inestimável orientação. 


\section{REFERẼNCIAS BIBLIOGRÁFICAS}

CHAPPEL, B.W. 1984. Source rocks of I- and S-type granites in the Lachland fold belt South-eastern Australia. Phill. Trans. R.Soc., A310:693-707.

CHAPPEL, B.W. \& WHITE, A.J.R. 1974. Two contrasting granit types, Pax. Geol., 8:173-174.

COX, K.G.; BELL, J.D.; PANKHURST, R.J. 1979. The interpretations of igneous rocks. London, G. Allen, $450 \mathrm{p}$.

HIBBARD, J.M. 1981. The magma mixing origin of mantled feldspars. Contributions to Mineralogy and Petrology, Berlin, 76:158-170.

HUTCHISON, C.S. 1974. Grain size, modal analysis, and photomicrography. Laboratory handbook of petrographic techniques. New York, J.Wiley. cap. 3, p. 44-72.

KAWASHITA, K.; CESAR, H.L; SCHRADER, G.O, 1976. The behavior of a solid source mass spectrometer with a glass tube and age determinations on some rocks from the state of Ceará, Brasil. An. Acad. bras. Ciênc., 43(1):79-86.

LAMEYRE, J. \& BOWDEN, P. 1982. Plutonic rocks types series. discrimination of various granitoids series and related rocks. Elsevier. Journal Volcandazy, 14:168-186,

LOISELLE, M.C. \& WONES, D.R. 1979. Characteristics and models for the origin of A-type granites. s.n.t. (não publucado).
PEACOCK, M.A. 1931. Classification of igneous rocks series. J.Geol., 39:54-67.

SOUZA, E. \& BRAGA, A.P. 1984. Mapeamento geologico da folha Itapiúna escala regional. Relatório. Ceminas, Fortaleza, 250 p..

STRECKEISEN, A.L. 1976. To each plutonic rocks its proper name. Earth Sci,Rev., 12:1-33.

WRITGH, T.L. 1969. Presentation and interpretation of chemical data for igneous rocks. Geol. Soc. Am. abstr. Prog., 2:727-729.

ZEN, E-an. 1985. Implications of magmatic epidote-bearing plutons on crustal evolution in the accreted terranes of northwestern North America. Geology, 13:266-269.

ZEN, E-an \& HAMMARSTROMM,J.M. 1984. Magmatic epidote and its petrologic significance. Geology, 12:515-518.

MANUSCRITO 555

Recebido em 17 de janeiro de 1988

Revisão recebida em 13 de outubro de 1988

Revisão aceita em 15 de dezembro de 1988

Newton não foi o primeiro da idade da razão. Ele foi o último dos magos, o último dos babilônios e sumérios, a última grande mente a olhar para o mundo visível e para o mundo intelectual com os mesmos olhos daqueles qué começaram a construir nossa herança intelectual há menos de 10.000 anos atrás. Por que o chamo de mago? Porque ele encarava o universo inteiro e tudo o que ele contém como um enigma, como um segredo que poderia ser lido aplicando o pensamento puro a certas evidências, certas chaves místicas que Deus havia posto no mundo de modo a permitir uma espécie de caça ao tesouro pela irmandade esotérica.

John Maynard Keynes. 1947. Newton, the man. Cambridge Univ. Pres. p. 41. 